\title{
Electroencephalographic changes and testosterone levels in a pubertal stress animal model: effects on adult sexual motivation
}

\author{
Marisela Hernández González, ${ }^{\prime}$ Enrique Hernández Arteaga, ${ }^{1}$ Miguel Ángel Guevara, ${ }^{1}$ Herlinda Bonilla Jaime, ${ }^{2}$ \\ Marcela Arteaga Silva²
}

Instituto de Neurociencias, Universidad de Guadalajara, Guadalajara, Jalisco, México.

2 Departamento de Biología de la Reproducción, Universidad Autónoma Metropolitana-lztapalapa, Ciudad de México, México.

\section{Correspondence:}

Marisela Hernández González Laboratorio de Neurofisiología de la Conducta Reproductiva, Instituto de Neurociencias, Universidad de Guadalajara.

Francisco de Quevedo 180

Col. Arcos-Vallarta

44130, Guadalajara, Jalisco, México. Phone: 52 (33) 3777 - 1150 , ext. 33360

Email: marisela.hgonzalez@

academicos.udg. $\mathrm{mx}$

Received: 20 September 2019

Accepted: 4 December 2019

Citation:

Hernández González, M. Hernández Arteaga, E., Guevara, M. A., Bonilla Jaime, H., Arteaga Silva, M. (2020). Electroencephalographic changes and testosterone levels in a pubertal stress animal model: effects on adult sexual motivation. Salud Mental, 43(1), 11 19.

DOI: $10.17711 /$ SM.0185-3325.2020.003

\begin{abstract}
Introduction. Stress during puberty exerts long-term effects on endocrine systems and brain structures, such as the prefrontal cortex (PFC) and basolateral amygdala (BLA), two cerebral areas that participate in modulating sexual behavior and whose functioning is regulated by androgenic hormones. Objective. To evaluate the effect of pubertal stress due to social isolation on the sexual motivation, serum testosterone levels, and electroencephalographic activity (EEG) of the PFC and BLA in male rats. Method. Sixty sexually-experienced male rats were used. Thirty were stressed by social isolation during puberty (SG, housed 1 per cage, postnatal days 25-50); the other 30 formed the control group (CG, 5 per cage). All rats were implanted bilaterally with stainless steel electrodes in the PFC and BLA. EEGs were recorded during the awake-quiet state in two conditions: without sexual motivation (WSM), and with sexual motivation (SM). After EEG recording, the rats were sacrificed by decapitation to measure their testosterone levels. Results. SG showed lower sexual motivation and testosterone levels, but higher amygdaline EEG activation in the presence of a receptive female, while CG showed higher prefrontal EEG activation. Discussion and conclusion. It is probable that the decreased testosterone levels resulting from pubertal stress affected prefrontal and amygdaline functionality and, hence, sexual motivation. These data could explain some of the hormonal and cerebral changes associated with stress-induced sexual alterations, though this suggestion requires additional clinical and animal research.
\end{abstract}

Keywords: Stress, social isolation, EEG, testosterone, sexual motivation, rats.

\section{RESUMEN}

Introducción. El estrés durante la pubertad ejerce efectos a largo plazo sobre sistemas endocrinos y estructuras cerebrales como corteza prefrontal (CPF) y amígdala basolateral ( $A B L)$. Ambas estructuras participan en la modulación de la conducta sexual y su funcionamiento es regulado por andrógenos. Objetivo. Evaluar los efectos del estrés puberal por aislamiento social sobre la motivación sexual, los niveles séricos de testosterona y la actividad electroencefalográfica (EEG) de la CPF y $A B L$ en ratas macho. Método. Se utilizaron sesenta ratas macho sexualmente expertas, 30 fueron estresadas por aislamiento social durante la pubertad (GE, hospedados 1 por caja, días 25 al 50 postnatal), y el resto conformó el grupo control (GC, hospedados 5 por caja). Las ratas fueron implantadas bilateralmente en la $C P F$ y $A B L$ y el EEG fue registrado durante estado vigilia-quieto en dos condiciones: sin motivación sexual (SMS) y con motivación sexual (MS). Finalmente, las ratas se sacrificaron por decapitación para medir los niveles de testosterona. Resultados. El GE presentó menor motivación sexual, menores niveles de testosterona y, en presencia de una hembra receptiva, presentaron una mayor activación EEG amigdalina, mientras que el GC mostró una mayor activación EEG prefrontal. Discusión y conclusión. Es probable que la disminución de los niveles de testosterona como resultado del estrés puberal haya afectado la funcionalidad prefrontal y amigdalina y, por ende, la motivación sexual. Estos datos pudieran explicar algunos de los cambios hormonales y cerebrales asociados con alteraciones sexuales producidas por estrés. Esta propuesta deberá explorarse en futuras investigaciones animales y clínicas.

Palabras clave: Estrés, aislamiento social, EEG, testosterona, motivación sexual, ratas. 


\section{INTRODUCTION}

Stress is a biological mechanism through which the body attempts to regain homeostasis when affected by stressors (Stratakis \& Chrousos, 1995). Research on mental health and sexual therapy describes that the stresses of daily life can drastically affect the quality of sexual activity by decreasing sexual satisfaction (Bodenmann, Ledermann, Blattner, \& Galluzo, 2006; Bodenmann, Ledermann, \& Bradbury, 2007). Moreover, the psychological symptoms associated with chronic stress (e.g., depression, anxiety) are directly related to lower sexual desire, erectile problems, premature ejaculation, and hypoactive sexual disorders (Bodenmann et al., 2007).

Animal models have also shown the deleterious effects of stress on sexual behavior (Retana-Márquez, Bonilla-Jaime, Vázquez-Palacios, Martínez-García, \& Velázquez-Moctezuma, 2003; Hernández-González, Guevara, Ramírez-Rentería, \& Hernández-Arteaga, 2015; Hernández-González et al., 2017), which can vary with stressor type, duration, and the period when it occurs (Lapiz et al., 2003; Vetulani, 2013; Hernández-Arteaga et al., 2016; Hernández-González et al., 2017). Puberty is a critical period for sexual maturation as important hormonal changes occur to allow adequate manifestations of sexual behavior during adulthood (Duffy \& Hendricks, 1973; Cooke, Chowanadisai, \& Breedlove, 2000; Hernández-González, 2000; Arteaga-Silva et al., 2013). Gonadal hormones like testosterone (T) and its metabolites (Bonilla-Jaime, Vázquez-Palacios, Arteaga-Silva, \& Retana-Márquez, 2006) are crucial to sexual behavior. However, some studies of adult male rats have found that after a period of stress glucocorticoid levels increase but $\mathrm{T}$ levels decrease, leading to the proposal that the hypothalamus-pituitary-adrenal (HPA) axis directly affects the hypothalamus-pituitary-gonad (HPG) axis to produce an antagonistic effect between the glucocorticoids and gonadal hormones (Retana-Márquez et al., 2003). Studies in men with stress-induced erectile dysfunction have similarly found lower T levels (Byun et al., 2013).

Pubertal stress in rats induced on postnatal days 2550 by social isolation is known to increase corticosterone concentrations (Serra, Pisu, Floris, \& Biggio, 2005; Perelló, Chacon, Cardinali, Esquifino, \& Spinedi, 2006), but reduce T secretion during a sexually-motivated state in adulthood (Amistislavskaya, Bulygina, Tikhonova, \& Maslova, 2013). Those rats also presented alterations in aromatase activity (Di Prisco, Lucarini, \& Dessi-Fulgheri, 1978), which aromatizes T into estradiol (Moralí, Larsson, \& Beyer, 1977; Muller, Van Den Beld, Van Der Schouw, Grobbe, \& Lamberts, 2006) and activates sexual motivation. These hormones produce non-genomic effects in the neuronal membrane that modulates the electrical activity of neurons in several brain areas (del Río-Portilla, Ugalde, Juárez, Roldán, \& Corsi-Cabrera, 1997; Joëls, 1997; Poblano et al., 2004; Balthazart, Baillien,
Cornil, \& Ball, 2004), including the medial prefrontal cortex (mPFC) and the basolateral amygdala (BLA), two cerebral structures that have androgen (Naghdi, Oryan, \& Etemadi, 2003; Nuñez, Huppenbauer, McAbee, Juraska, \& DonCarlos, 2003), estrogen (Montague et al., 2009; Lonc, 2012), and glucocorticoid (Pryce, 2008) receptors. The BLA has strong connections with the mPFC, especially layers II and V, in rodents (Cunningham, Bhattacharyya, \& Benes, 2002). This connectivity participates in various complex processes, including emotional memory on inhibitory avoidance tasks (Cahill \& McGaugh, 1991), aversive Pavlovian conditioning (Fanselow \& LeDoux, 1999), and goal-oriented behaviors using motivational odors as reinforcers (Schoenbaum, Chiba, \& Gallagher, 2000). Thus, they have been implicated in the processing of sexually-relevant stimuli and the regulation of sexual motivation (Fernández-Guasti, Omaña-Zapata, Luján, \& Condés-Lara, 1994; Ågmo, Villalpando, Picker, \& Fernández, 1995; Hernández-González, Guevara, \& Ågmo, 2014a; Hernández-González, Robles Aguirre, Guevara, Quirarte, \& Haro-Magallanes, 2014b). The processing of sexual stimuli and sexual motivation have been associated with electroencephalographic (EEG) activity characterized by a prevalence of slow frequencies in the 4-13 Hz (Hernández-González, Guevara, Cervantes, Moralí, \& Corsi-Cabrera, 1998; Hernández-González, Prieto-Beracoechea, Arteaga-Silva, \& Guevara, 2007; Hernández-González et al., 2014a) and 14-30 Hz bands (Hernández-González et al., 2017) in both the BLA and the mPFC.

Ågmo (1999) defines sexual motivation as the process that leads an individual to search for sexual contact with another. It is measured by approaching behaviors towards the potential sexual partner (Ventura-Aquino \& Paredes, 2017). These behaviors during rats' sexual interaction satisfy the criteria of correlation and homology with human sexual motivation (Ågmo, 2017).

While many studies have reported the deleterious effects that stress exerts on sexual behavior in animals and humans (Retana-Márquez et al., 2003; Byun et al., 2013; Hernández-González et al., 2015; 2017), few have examined hormonal and cerebral changes associated with sexual motivation in male rats that are stressed during puberty (Cooke et al., 2000; Amistislavskaya et al., 2013). Thus, the aim of this study was to determine the effects of stress experienced during puberty on sexual motivation, serum $T$ levels and $\mathrm{mPFC}$, and BLA functionality in adult male rats.

\section{METHOD}

\section{Animals}

At age 22 days, 60 male rats were weaned and housed in groups of five per cage. On day 25, they were randomly classified into two groups ( $n=30$ /group) called stressed 
(SG) and control (CG). The SG rats were housed only one per cage and remained socially-isolated until day 51, when they were re-socialized with their former mates. CG, meanwhile, remained undisturbed on all days. Figure 1 presents a timeline of the general procedure.

\section{Sexual interaction tests}

At age three months (weight $=250-350 \mathrm{~g}$ ), the rats were subjected to three copulatory tests (every second day) between 10:00 and 13:00 h. All 60 rats presented intromission on the three tests and reached ejaculation on at least two.

\section{Stereotaxic surgery}

The rats were injected subcutaneously with atropine sulfate $(.1 \mathrm{mg} / \mathrm{kg})$ and anesthetized with sodium pentobarbital (47 $\mathrm{mg} / \mathrm{kg}$ i.p.). Stainless steel electrodes (.2 $\mathrm{mm}$ in diameter) were implanted bilaterally into the prelimbic area of the $\mathrm{mPFC}(3.2 \mathrm{~mm}$ anterior to bregma, $1 \mathrm{~mm}$ lateral to midline, and $4.0 \mathrm{~mm}$ below the duramater), and the basolateral amygdala (BLA) (2.8 $\mathrm{mm}$ posterior to bregma, $5 \mathrm{~mm}$ lateral to midline, and $8.4 \mathrm{~mm}$ below the duramater), with the incisor bar set at $-3.3 \mathrm{~mm}$, following the stereotaxic atlas of Paxinos and Watson (2007). Two stainless steel screws were placed in the posterior area of the skull as reference and ground electrodes, respectively. All electrodes were attached to a miniature connector fixed to the skull with stainless steel hooks and acrylic cement. After surgery, all rats were housed in individual cages with food and water $a d$ libitum. The post-surgical recovery period was seven days.

\section{Experimental design}

\section{Sexual incentive motivation box}

The sexual incentive motivation box was a transparent plexiglas testing chamber $(64 \mathrm{~cm} \times 40 \mathrm{~cm} \times 34 \mathrm{~cm})$ divided in two equal compartments by a transparent acrylic partition with several 7-mm diameter holes. A male rat was placed in one compartment, and a stimulus female in the other such that they could see, hear, and smell each other, but no direct contact was possible. In the male's compartment, a line was drawn dividing it in two sections. The section closest to the female's compartment was considered the incentive zone.

\section{Recording conditions}

On the day of the experiment, each male was placed in the sexual incentive motivation box and connected to the polygraph to record EEG activity under two behavioral conditions: without (WSM) and with sexual motivation (SM). In the WSM condition, they were stimulated for five minutes with an ovariectomized (non-receptive) female in the other compartment, while in the SM condition they were allowed one intromission with a receptive female to induce a sexually-motivated state. Immediately afterwards, the female was transferred to the other compartment for five minutes to stimulate the male. The time in seconds that the males in both groups spent in the incentive zone was recorded.

\section{Testosterone sample}

Half of the males from CG and SG were decapitated immediately after EEG-recording in each condition (WSM and $\mathrm{SM})$. Blood samples measuring $8.5 \mathrm{ml}$ per subject were col-

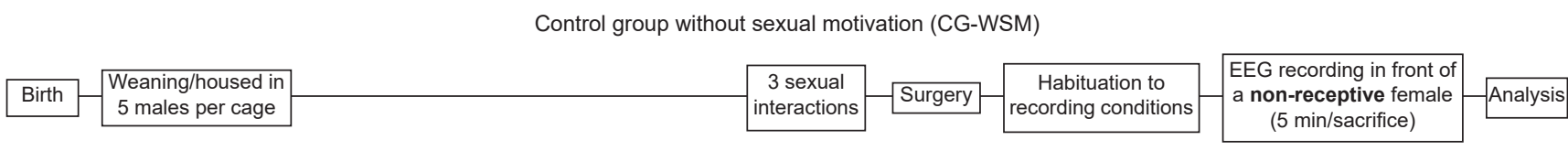

Control group with sexual motivation (CG-SM)

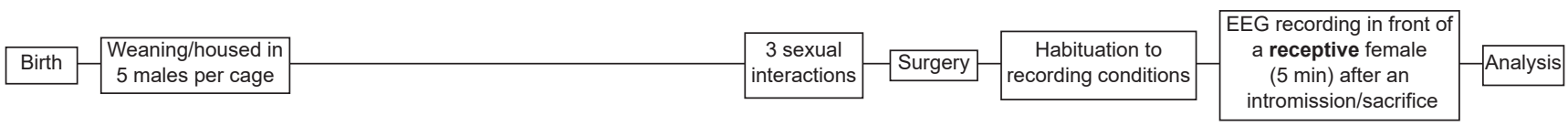

Stress group without sexual motivation (CG-WSM)

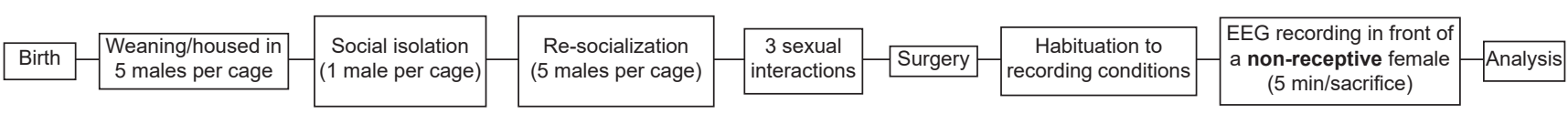

Stress group with sexual motivation (CG-SM)

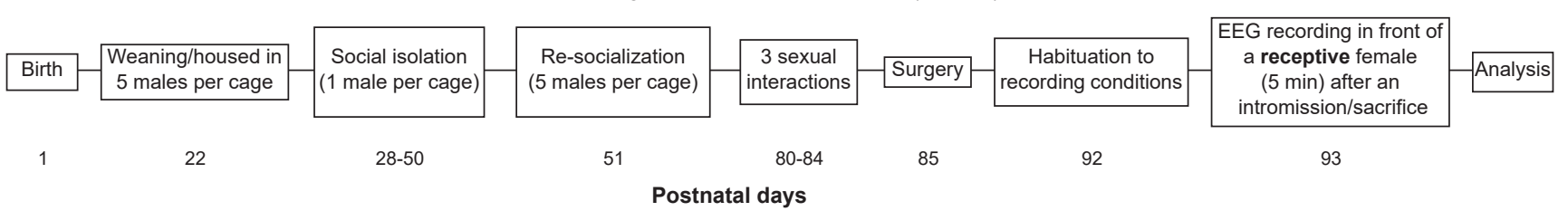

Figure 1. Timeline of the general procedure for each group. 
lected in test tubes (BD Vacutainer, ref 367988) containing gel to separate the blood serum. The samples were centrifuged at $3000 \mathrm{rpm}$ for 15 minutes and then the supernatant was recovered and stored in Eppendorf tubes at $-4^{\circ} \mathrm{C}$ for further analysis.

\section{EEG recording}

The bilateral $\mathrm{mPFC}$ and BLA electrodes were connected to a Model 7B GRASS polygraph with a recording window of $1-75 \mathrm{~Hz}$ to record EEGs during the awake-quiet state in the WSM and SM conditions. The polygraph was attached to an analogue-digital converter (CAD, Advantech Co., Mod. PCL-812). The sample rate was $1024 \mathrm{~Hz}$. All EEGs were stored on a PC for offline analysis.

\section{EEG analysis}

Only the EEG recordings that were free of noise or movement artifacts were included in data analysis. The Absolute Power (AP, defined as the power density of each frequency expressed in microvolts $\left.{ }^{2}\right)$ of four EEG bands (4-7, 8-13, 1430, 31-50 Hz) was calculated using Fast Fourier Transformation (FFT). To approximate a normal distribution, the AP values were transformed into natural logarithms.

\section{Testosterone analysis}

Serum $\mathrm{T}$ concentrations were obtained using the ELISA technique with the commercial preparation called the "Testosterone enzyme immunoassay" kit (catalog \# 611CH; estimated sensitivity $=.05 \mathrm{ng} / \mathrm{mL}$ ). With all reagents and samples at room temperature, $10 \mu \mathrm{L}$ of the standards, the target and one sample were pipetted into each well of the kit and $50 \mu \mathrm{L}$ of rabbit anti-T reagent were added. This mixture was then homogenized for 30 seconds. Next, $100 \mu \mathrm{L}$ of HRP T conjugate reagent were added and the mixture was incubated for 90 minutes at $37^{\circ} \mathrm{C}$. The microplate was washed and rinsed five times with wash solution; then $100 \mu \mathrm{L}$ of TMB reagent were added to each well and mixed for 10 seconds. This mixture was incubated at room temperature for $20 \mathrm{~min}-$ utes, before adding $100 \mu \mathrm{L}$ of stop solution. This was mixed for 30 seconds and read at an optical density of $450 \mathrm{~nm}$. Finally, the data obtained from the standards were used to build a calibration curve that was applied to calculate the $\mathrm{T}$ concentration of each sample $(\mathrm{ng} / \mathrm{ml})$.

\section{Histology}

The rats' brains were fixed by an intracardial infusion of isotonic saline $(.9 \%)$ followed by a $5.0 \%$ buffered paraformaldehyde solution. They were then removed and stored in formyl for at least two weeks. Sections $50 \mu$-thick were cut with a microtome and stained with cresyl violet. Inspection under a stereoscopic microscope to trace the stereotaxic coordinates allowed us to reconstruct the path followed by the recording electrode.

\section{Statistical analyses}

The serum $\mathrm{T}$ concentrations from the four sub-groups (SGWSM, SG-SM, CG-WSM, and CG-SM) were compared by a two-way ANOVA. The time spent in the incentive zone was compared between CG-SM and SG-SM using a Student $\mathrm{T}$ test, followed by a Cohen $\mathrm{d}$ test to calculate effect size. For the EEG data, a two-way ANOVA (groups $\times$ condition) was used to compare the AP of each frequency band recorded in the control and stressed sub-groups ( $n=15 /$ subgroup) under the WSM and SM conditions. A Tukey HDS test was performed for a posteriori comparisons, followed by a Cohen $\mathrm{d}$ test to calculate effect size. We calculated the effect size, $\eta^{2}$, for the effect of experimental condition and interaction. If only one or two factors were significant in the ANOVA, an exploratory analysis was performed using a Student-t test with Bonferroni correction in all comparisons, followed by a Cohen $d$ test to calculate effect size.

\section{Ethical considerations}

Adequate care was taken to minimize the animals' pain and discomfort throughout the experiment. All procedures were carried out following a protocol approved by the local Animal Ethics Committee (ET062017-250) in compliance with national (NOM-062-ZOO-1999) and international (NIH) regulations on the care and use of laboratory animals.

\section{RESULTS}

\section{Testosterone levels}

The ANOVA showed only a significant difference for the factor groups, with a medium effect size $\left[\mathrm{F}(\mathrm{A})=4.07, p\left(\mathrm{~F}_{\mathrm{A}}\right)\right.$ $=.0485 ; \eta 2=.065] . \mathrm{SG}$ had lower serum $\mathrm{T}$ levels than CG (between-groups comparison with both conditions as a factor in the ANOVA; Figure 2). No differences were found in any of the comparisons in the exploratory analysis (mean \pm 2 S.E. of serum $T$ levels $(\mathrm{ng} / \mathrm{mL})$ measured in CG-WSM: $4.12 \pm 1.12$; CG-SM: $4.44 \pm .87$; SG-WSM: $2.74 \pm .87$; SG-SM: $3.67 \pm .86$ ).

\section{Time spent in the incentive zone}

The SG-SM subjects remained in the incentive zone (i.e., in the presence of a receptive female) for less time ( 99.067 \pm 17.825 seconds $)$ than the CG-SM rats $(155.867 \pm 18.616$ seconds). This produced a medium effect size of $\left(\mathrm{t}\left[{ }_{28}\right]=\right.$ $2.20, p[\mathrm{t}]=.0359 ; \mathrm{d}=.756)$.

\section{Histological analysis}

The electrode tips in the mPFC were placed between 3.7$3.2 \mathrm{~mm}$ anterior to bregma, $.5-1.5 \mathrm{~mm}$ lateral to midline, 


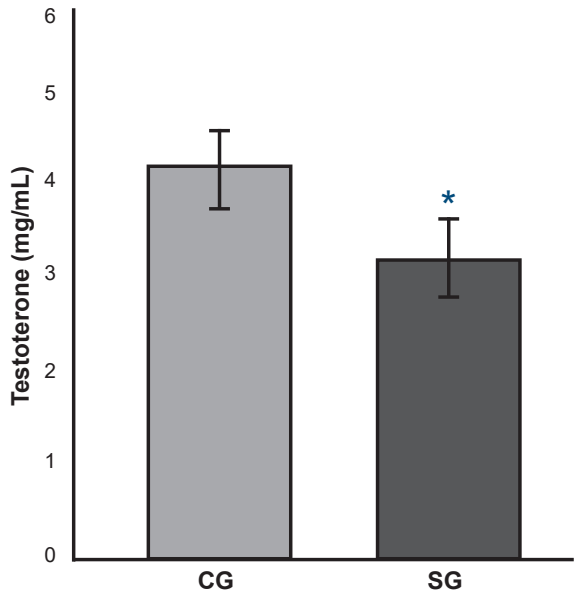

Figure 2. Mean \pm 2 S.E. of serum testosterone levels $(\mathrm{ng} / \mathrm{mL})$ measured in the control (CG, white bar, $n=30)$ and stressed groups (SG, gray bar, $n=30) .{ }^{*} p(F) \leq .05$ SG compared to CG.

and 3.8-4.2 below the dura mater (in the prelimbic region of the PFC), while in the BLA they were placed between 2.62.7 posterior to bregma, $4.2-5.0 \mathrm{~mm}$ lateral to midline, and $8.0-9.0 \mathrm{~mm}$ below the dura mater (Figure 3 ).

\section{Absolute power}

\section{Left medial prefrontal cortex ( $m P F C$ )}

The ANOVA only showed significant differences for the factor condition for all frequency bands $[4-7 \mathrm{~Hz} \mathrm{~F}(\mathrm{~B})=6.68$, $p\left(\mathrm{~F}_{\mathrm{B}}\right)=.01455 ; \eta^{2}=.040$ (small effect size); $8-13 \mathrm{~Hz}: \mathrm{F}(\mathrm{B})=$ $15.75, p\left(\mathrm{~F}_{\mathrm{B}}\right)=.00072 ; \eta^{2}=.076$ (medium effect size); $14-30$ Hz: $\mathrm{F}(\mathrm{B})=17.79, p\left(\mathrm{~F}_{\mathrm{B}}\right)=.00044 ; \eta^{2}=.076$ (medium effect size); 31-50 Hz: $\mathrm{F}(\mathrm{B})=18.29, p\left(\mathrm{~F}_{\mathrm{B}}\right)=.00039 ; \eta^{2}=.040$ (small effect size)]. In all bands, the rats (between-conditions comparison with both groups as a factor in the ANOVA) presented higher AP under the SM condition than WSM (Table 1).

In the exploratory analysis (Student's t-test comparing both conditions in each group separately), CG showed a higher AP of the $8-13 \mathrm{~Hz}[\mathrm{t}(28)=2.887, p(\mathrm{t})=.01194 ; \mathrm{d}=.634$ (medium effect size) $]$; $14-30 \mathrm{~Hz}[\mathrm{t}(28)=2.956, p(\mathrm{t})=.01042$; $\mathrm{d}=.572$ (medium effect size)]; and 31-50 Hz $[\mathrm{t}(28)=4.249$,
A
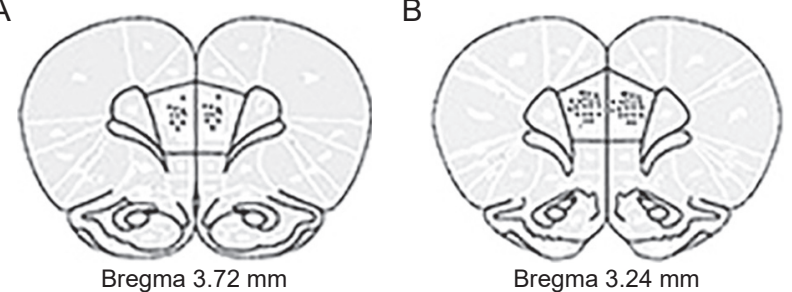

C

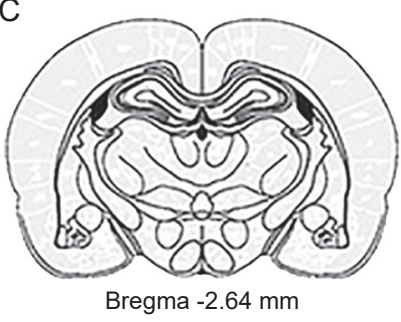

$\mathrm{D}$

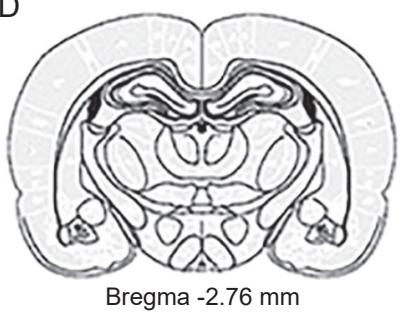

Figure 3. Schematic representation of electrode tip placement in the mPFC (A-B) and BLA (C-D). Anterior-posterior coordinates are given with respect to bregma following the stereotaxic atlas of Paxinos \& Watson (2007). Dots represent the electrode tips implanted in each rat of sub-groups CG-SM $(n=15)$ and SG-SM $(n=15)$.

$p(\mathrm{t})=.00081 ; \mathrm{d}=.398$ (small effect size)] during SM compared to WSM (Figure 4A). SG only showed a higher AP of the $8-13 \mathrm{~Hz}[\mathrm{t}(28)=2.965, p(\mathrm{t})=.01024 ; \mathrm{d}=.448$ (small effect size $)]$, and $14-30 \mathrm{~Hz}$ bands $[\mathrm{t}(28)=3.105, p(\mathrm{t})=.0076$; $\mathrm{d}=.529$ (medium effect size)] (Figure 4B).

\section{Right medial prefrontal cortex ( $m P F C$ )}

The ANOVA showed only significant differences for the factor condition for all frequency bands $[4-7 \mathrm{~Hz} \mathrm{~F}(\mathrm{~B})=8.64$, $p\left(\mathrm{~F}_{\mathrm{B}}\right)=.00656 ; \eta^{2}=.030$ (small effect size) $] ;[8-13 \mathrm{~Hz} \mathrm{~F}(\mathrm{~B})$ $=19.84, p\left(\mathrm{~F}_{\mathrm{B}}\right)=.00028 ; \eta^{2}=.062$ (medium effect size); 14$30 \mathrm{~Hz} \mathrm{~F}\left({ }_{\mathrm{B}}\right)=17.92, p\left(\mathrm{~F}_{\mathrm{B}}\right)=.00042 ; \eta^{2}=.053$ (small effect size); $\left.31-50 \mathrm{~Hz} \mathrm{~F}_{\mathrm{B}}\right)=9.28, p\left(\mathrm{~F}_{\mathrm{B}}\right)=.00516 ; \eta^{2}=.025$ (small effect size)]. In all cases, the rats (between-conditions comparison with both groups as a factor in the ANOVA) presented higher AP during SM than WSM (Table 1).

In the exploratory analysis (Student's t-test comparing both conditions in each group separately), CG showed a higher $\mathrm{AP}$ of frequency bands $8-13 \mathrm{~Hz}[\mathrm{t}(28)=4.043, p(\mathrm{t})=$ $.00121 ; \mathrm{d}=.498$ (small effect size) $] ; 14-30 \mathrm{~Hz}[\mathrm{t}(28)=3.793$,

Table 1

Means of the absolute power (transformed into logarithms) of the EEG bands recorded in the left and right medial prefrontal cortex (MPFC) and basolateral amygdale (BLA) during the conditions without (WSM) and with sexual motivation (SM)

\begin{tabular}{|c|c|c|c|c|c|c|c|c|c|c|c|c|}
\hline & \multicolumn{3}{|c|}{ 4-7 Hz } & \multicolumn{3}{|c|}{$8-13 \mathrm{~Hz}$} & \multicolumn{3}{|c|}{$14-30 \mathrm{~Hz}$} & \multicolumn{3}{|c|}{$31-50 \mathrm{~Hz}$} \\
\hline & WSM & $S M$ & $M D$ & WSM & $S M$ & $M D$ & WSM & $S M$ & $M D$ & WSM & $S M$ & $M D$ \\
\hline Left mPFC & 12.4 & 12.7 & $.3 \pm .2^{*}$ & 12.1 & 12.4 & $.4 \pm .2^{*}$ & 11.5 & 12.0 & $.4 \pm .2^{*}$ & 10.0 & 10.3 & $1.1 \pm .3^{*}$ \\
\hline Right mPFC & 12.6 & 12.9 & $.3 \pm .2^{*}$ & 12.2 & 12.5 & $.3 \pm .1^{*}$ & 11.7 & 12.0 & $.3 \pm .1^{*}$ & 10.2 & 10.4 & $.2 \pm .1^{*}$ \\
\hline Left BLA & 12.7 & 13.0 & $.3 \pm .2^{*}$ & 12.5 & 12.8 & $.2 \pm .1^{*}$ & 12.5 & 12.4 & $.2 \pm .1^{*}$ & 10.2 & 10.4 & $.2 \pm .1^{*}$ \\
\hline Right BLA & 12.7 & 12.8 & $.1 \pm .1$ & 12.5 & 12.6 & $.2 \pm .1^{*}$ & 12.2 & 12.3 & $.2 \pm .1^{*}$ & 10.6 & 10.5 & $.1 \pm .2$ \\
\hline
\end{tabular}

Note: The mean difference between conditions (MD) \pm 2 S.E. is also indicated. It represents the factor 'conditions', so comparisons were performed with $n=30$ for both groups and in each condition. ${ }^{*} p\left(\mathrm{~F}_{\mathrm{B}}\right) \leq .05, \mathrm{SM}$ as compared to WSM. 

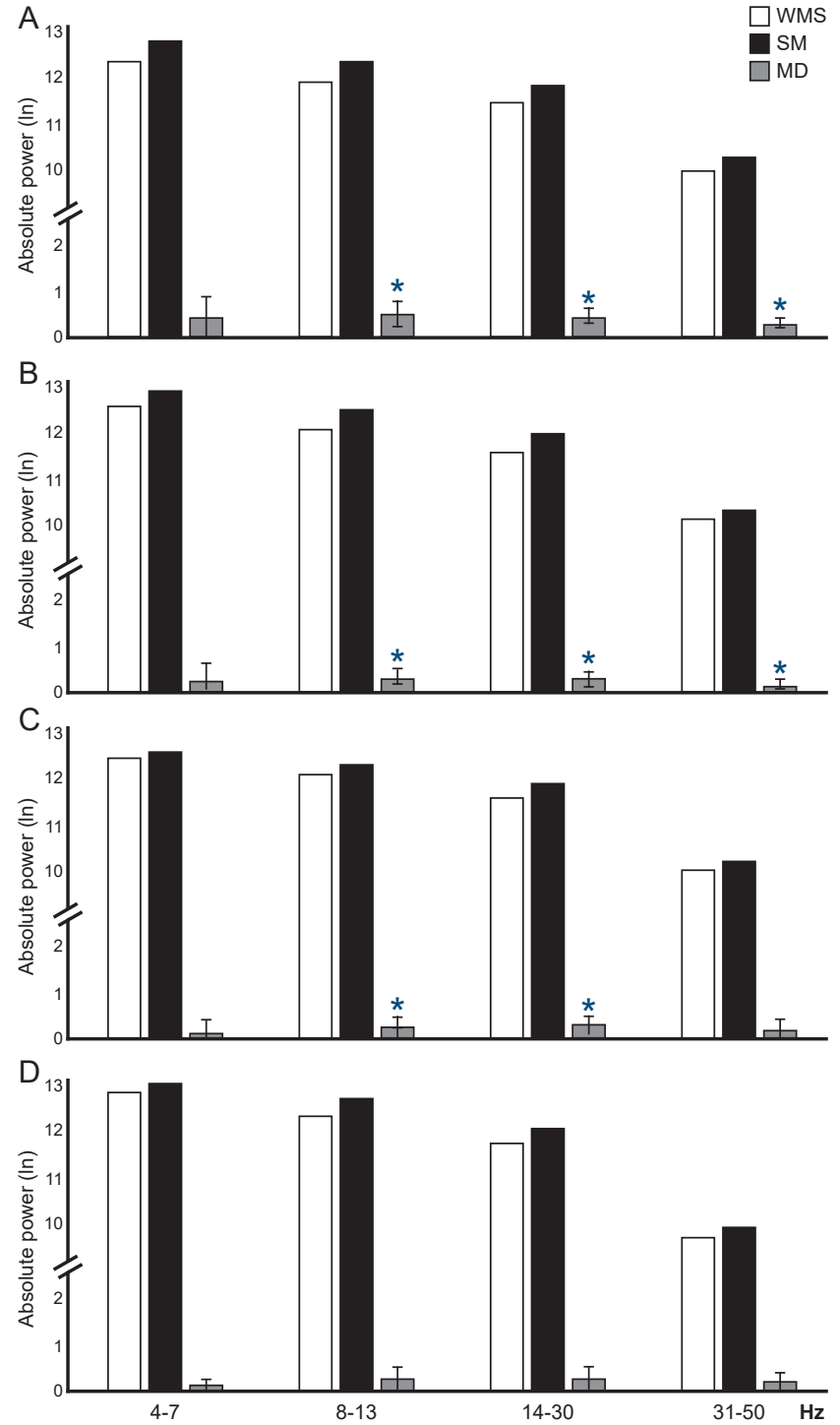

Figure 4. Mean of the absolute power (AP, transformed into logarithms) of the EEG bands recorded in the left mPFC of CG $(A)$ and SG (B) and right mPFC of CG (C) and SG (D) during the two conditions: without (WSM, white bars) and with sexual motivation (SM, dark bars). Gray bars represent the mean difference \pm 2 S.E. $(n=15 /$ group). ${ }^{*} p(T) \leq .0125$ SM compared to WSM.

$p(\mathrm{t})=.00198 ; \mathrm{d}=.411($ small effect size $)] ;$ and $31-50 \mathrm{~Hz}$ $\left[\mathrm{t}_{28}\right)=2.958, p(\mathrm{t})=.01038 ; \mathrm{d}=.294$ (small effect size $\left.)\right]$ during SM compared to WSM (Figure 4C). SG showed no significant differences between conditions (Figure 4D).

\section{Left basolateral amygdala}

The ANOVA only showed significant differences for the factor condition for all frequency bands. All analyses reached only a small effect size: $4-7 \mathrm{~Hz}\left[\mathrm{~F}\left({ }_{\mathrm{B}}\right)=7.84, p\left(\mathrm{~F}_{\mathrm{B}}\right)=.00897\right.$; $\left.\eta^{2}=.013 .8-13 \mathrm{~Hz} \mathrm{~F}\left({ }_{\mathrm{B}}\right)=14.07, p\left(\mathrm{~F}_{\mathrm{B}}\right)=.00112 ; \eta^{2}=.013\right]$; $14-30\left[\mathrm{~Hz} F\left({ }_{\mathrm{B}}\right)=11.56, p\left(\mathrm{~F}_{\mathrm{B}}\right)=.00236 ; \eta^{2}=.010\right]$; and 31$50 \mathrm{~Hz}\left[\mathrm{~F}(\mathrm{~B})=9.88, p\left(\mathrm{~F}_{\mathrm{B}}\right)=.00415 ; \eta^{2}=.010\right]$. In all cases,
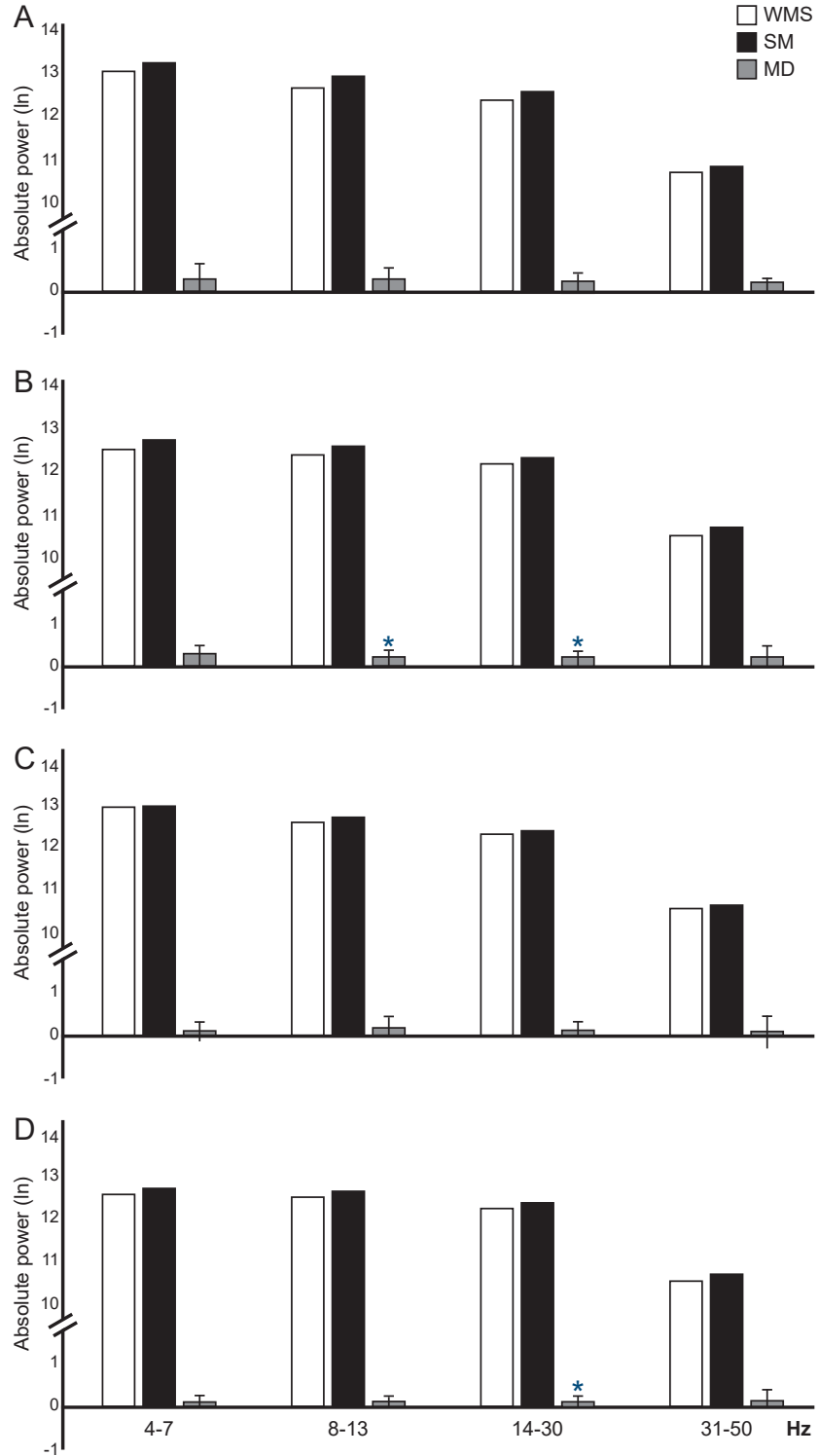

Figure 5. Mean of the absolute power (AP, transformed into logarithms) of the EEG bands recorded in the left BLA of CG (A) and SG (B) and the right BLA of CG (C) and SG (D) during the two conditions: without (WSM, white bars), and with sexual motivation (SM, dark bars). Gray bars represent the mean difference \pm 2 S.E. $(n=15 /$ group). ${ }^{*} p(T) \leq .0125$ SM compared to WSM.

the rats (between-conditions comparison with both groups as a factor in the ANOVA) presented a higher AP during SM than WSM (Table 1).

In the exploratory analysis (Student's t-test comparing both conditions in each group separately), CG showed no significant differences in the AP of the EEG bands between conditions (Figure 5A). SG had higher AP during SM than WSM in the 8-13 $\left.\left[\mathrm{t}_{28}\right)=2.873, p(\mathrm{t})=.001228 ; \mathrm{d}=.303\right]$ and $14-30 \mathrm{~Hz}[\mathrm{t}(28)=3.038, p(\mathrm{t})=.00887 ; \mathrm{d}=.322]$ bands, both with a small effect size (Figure 5B). 


\section{Right basolateral amygdala}

The ANOVA showed only significant differences for the factor condition for the 8-13 $\left[\mathrm{F}(\mathrm{B})=5.62, p\left(\mathrm{~F}_{\mathrm{B}}\right)=.02352\right.$; $\left.\eta^{2}=.010\right]$ and $14-30 \mathrm{~Hz}\left[\mathrm{~F}(\mathrm{~B})=4.17, p\left(\mathrm{~F}_{\mathrm{B}}\right)=.04813 ; \eta^{2}=\right.$ $.010]$ bands, both with a small effect size. In both cases, the rats (between-conditions comparison with both groups as a factor in the ANOVA) had higher AP during SM than WSM (Table 1).

In the exploratory analysis (Student's t-test comparing both conditions in each group separately), CG showed no significant differences between conditions (Figure 5C), while SG had higher AP during SM than WSM in the 14-30 $\mathrm{Hz}$ band, with a small effect size $[\mathrm{t}(28)=3.001, p(\mathrm{t})=.00508$; $\mathrm{d}=.283]$ (Figure 5D).

\section{DISCUSSION AND CONCLUSION}

By taking advantage of the benefits of the rat as a model of sexual behavior, and using an ad hoc experimental stress paradigm, this study found that the effects of pubertal stress prevail into adulthood by altering brain functionality, serum $\mathrm{T}$ levels, and sexual motivation in male rats. The experiment evaluated the time spent in the sexual incentive zone to measure sexual motivation, finding that the stressed rats spent significantly less time there, which demonstrates that sexual motivation was affected by the stress induced during puberty, as other studies have reported (Gerall, Ward, \& Gerall, 1967; Duffy \& Hendricks, 1973; Cooke et al., 2000; Hernández-González et al., 2015). Also, the rats presented lower serum $\mathrm{T}$ levels, which confirm the deleterious effects of stress during puberty on the activation of the HPG axis in male rats (Amistislavskaya et al., 2013).

Other studies have shown that sexual motivation in male rats is related to increased serum $\mathrm{T}$ levels (Bonilla-Jaime et al., 2006). During puberty, this hormone plays an organizational role that facilitates the morphological and behavioral changes associated with sexual maturation (Hernández-González, 2000; Schulz et al., 2004; Arteaga-Silva et al., 2013; Hernández-González et al., 2015). As mentioned previously, corticosterone exerts a negative effect on T levels (Retana-Márquez et al., 2003), so it is likely that the stress paradigm used herein increased corticosterone levels (Serra et al., 2005; Perelló et al., 2006; Amistislavskaya et al., 2013) during puberty and so exerted a long-term negative effect on $\mathrm{T}$ levels that led the stressed rats to manifest lower levels than controls in adulthood.

We decided to evaluate prefrontal and amygdaline functionality because these two areas are interconnected in rodents (Cunningham et al., 2002) and participate in various complex processes, including goal-oriented behaviors using motivational odors as reinforcers (Schoenbaum et al., 2000). This means that they are implicated, as well, in the processing of sexually-relevant stimuli (Fernández-Guasti et al., 1994; Ågmo et al., 1995; Hernández-González et al., 2014a; 2014b). In addition, both regions contain androgen receptors (Naghdi et al., 2003; Nuñez et al., 2003). In this context, the study evidenced that the CG and SG rats had distinct activations of these structures during the perception and processing of the stimuli emitted by the receptive and non-receptive females. In male rats, the 4-7 and 8-13 $\mathrm{Hz}$ EEG bands are associated with approach behaviors to incentive stimuli, attention (Vanderwolf, 1969; Bland \& Whishaw, 1976; Hernández-González et al., 1998), and motivated states (Hernández-González et al., 2014a), while the fast frequencies $(14-50 \mathrm{~Hz})$ - in both animal and human models - have been related to the higher processing that underlies stimuli selection (Başar, Başar-Eroğlu, Karakaş, \& Schürmann, 2000; Engel \& Singer, 2001).

Only CG showed a higher AP in almost all bands in the left and right $\mathrm{mPFC}$ when a receptive female was present, compared to a non-receptive one. The mPFC is involved in attention, the processing of sensory stimuli emitted by a potential partner, and the assigning of incentive value, three processes that are necessary for the onset of sexual behavior (Ågmo et al., 1995; Hernández-González et al., 2014a; Hernández-González et al., 2017). Thus, it is probable that the higher activation of the mPFC in CG is associated with a greater degree of attention given to the sexually-receptive female and, hence, greater sexual motivation, as evidenced by the longer time they spent near the receptive female.

SG only showed EEG changes in the left $\mathrm{mPFC}$ in the presence of the receptive female, but with lower sexual motivation. Thus, it is likely that their lower $\mathrm{T}$ levels altered the $\mathrm{mPFC}$ activity, leading to inadequate processing of the sexually-relevant stimuli. Moreover, the stressed males had a higher AP of the EEG bands in the left and right BLA. Pubertally-stressed rats exhibit higher amygdaline activity (Wang, Ho, Ko, Liao, \& Lee, 2012) associated with anxiety-like behaviors (Zhang \& Rosenkranz, 2012), together with higher concentrations of dopaminergic receptors (D2) in the BLA (Djouma, Card, Lodge, \& Lawrence, 2006). It is well-known that D2 activation inhibits sexual behavior (Balthazart, Castagna, \& Ball, 1997). Higher amygdaline activity has also been observed in patients with social anxiety disorder in response to socially-aversive stimuli (Kraus et al., 2018), so it may be that as a result of greater amygdaline activation our pubertally-stressed male rats had difficulty in processing and assigning incentive value to the stimuli emitted by the female.

Lower sexual motivation in non-human animals can be operationalized as a feature of hypoactive sexual desire disorder in humans. Patients with this disorder report that sexual partners can seem aversive (for a discussion, see Ågmo, Turi, Ellingsen, \& Karpersen, 2004). Leussis and Andersen (2008) demonstrated that rats stressed by social isolation during puberty show depression-like behaviors, so it may be that the generation of depression-like effects in these rats 
means they process the female's stimuli as socially-aversive instead of sexually-relevant. However this affirmation will require further analyses with rats.

It is likely that pubertal stress decreased $\mathrm{T}$ levels and exerted long-term effects on the functionality of prefrontal and amygdaline areas. Hence, the stressed males failed to perceive the receptive female as a pleasant, rewarding stimuli. However, this hypothesis also needs to be explored in future clinical and animal research.

\section{Funding}

This work was supported by a grant from the Programa de Fortalecimiento de la Investigación y el Posgrado $(131-4,2017)$ assigned to MHG.

\section{Conflict of interest}

The authors declare that they have no conflicts of interest.

\section{Acknowledgments}

We thank Paul Kersey for proofreading the English version of this manuscript.

\section{REFERENCES}

Ågmo, A. (1999). Sexual motivation - an inquiry into events determining the occurrence of sexual behavior. Behavioural Brain Research, 105(1), 129-150. doi: 10.1016/S0166-4328(99)00088-1

Ågmo, A. (2017). ¿Tienen los estudios psicobiológicos, en animales no humanos, alguna relevancia para la conducta humana? El caso de la conducta sexual. In A. C. Medina-Fragoso, M. Hernández-González, C. Amezcua-Gutiérrez, \& M. A. Guevara (Eds.), Psicobiología conductual y cognitiva. (pp. 29-51). México: Universidad Nacional Autónoma de México.

Ågmo, A., Turi, A. L., Ellingsen, E., \& Karpersen, H. (2004). Preclinical models of sexual desire: conceptual and behavioral analyses. Pharmacology, Biochemistry, and Behavior, 78(3), 379-404. doi: 10.1016/j.pbb.2004.04.013

Ågmo, A., Villalpando, A., Picker, Z., \& Fernández, H. (1995). Lesions of the medial prefrontal cortex and sexual behavior in the male rat. Brain Research, 696(1-2), 177-186. doi: 10.1016/0006-8993(95)00852-H

Amistislavskaya, T. G., Bulygina, V. V., Tikhonova, M. A., \& Maslova, L. N. (2013). Social isolation during peri-adolescence or adulthood: effects on sexual motivation, testosterone, and corticosterone response under conditions of sexual arousal in male rats. Chinese Journal of Physiology, 56(1), 36-43. doi: 10.4077/ CJP.2013.BAA074

Arteaga-Silva, M., Vigueras Villaseñor, R. M., Retana Márquez, S., Hernández González, M., Bonilla Jaime, H., Guzmán García, X., \& Contreras Montiel, J. L. (2013). Testosterone levels and development of the penile spines and testicular tissue during the postnatal growth in wistar rats. Advances in Sexual Medicine, 3(3), 1-9. doi: 10.4236/asm.2013.33A001

Balthazart, J., Baillien, M., Cornil, C. A., \& Ball, G. F. (2004). Preoptic aromatase modulates male sexual behavior: slow and fast mechanisms of action. Physiology \& Behavior, 83(2), 247-270. doi: 10.1016/j.physbeh.2004.08.025

Balthazart, J., Castagna, C., \& Ball, G. F. (1997). Differential effects of D1 and D2 dopamine-receptor agonists and antagonists on appetitive and consumatory aspects of male sexual behavior in Japanese quail. Physiology \& Behavior, 62(3), 571-580. doi: 10.1016/S0031-9384(97)00163-7

Başar, E., Başar-Eroğlu, C., Karakaş, S., \& Schürmann, M. (2000). Brain oscillations in perception and memory. International Journal of Psychophysiology, 35(2-3), 95-124. doi: 10.1016/S0167-8760(99)00047-1

Bland, B. H., \& Whishaw, I. Q. (1976). Generators and topography of hippocampal Theta (RSA) in the anesthetized and freely moving rat. Brain Research, 118(2), 259-280. doi: 10.1016/0006-8993(76)90711-3
Bodenmann, G., Ledermann, T., \& Bradbury, T. N. (2007). Stress, sex and satisfaction in marriage. Personal Relationship, 14(4), 551-569. doi: 10.1111/j.14756811.2007.00171.x

Bodenmann, G., Ledermann, T., Blattner, D., \& Galluzo, C. (2006). Associations among everyday stress, critical life events, and sexual problems. The Journal of Nervous and Mental Disease, 194(7), 494-501. doi: 10.1097/01. nmd.0000228504.15569.b6

Bonilla-Jaime, H., Vázquez-Palacios, G., Arteaga-Silva, M., \& Retana-Márquez, S. (2006). Hormonal responses to different sexually related conditions in male rats. Hormones \& Behavior, 49(3), 376-382. doi: 10.1016/j.yhbeh.2005.08.005

Byun, J. S., Lyu, S. W., Seok, H. H., Kim, W. J, Shim, S. H., \& Bak, C. W. (2013). Sexual dysfunctions induced by stress of timed intercourse and medical treatment. British Journal of Urology International, 111(4b), E227-E234. doi: 10.1111/j.1464-410X.2012.11577.x

Cahill, L., \& McGaugh, J. L. (1991). NMDA-induced lesions of the amygdaloid complex block the retention-enhancing effect of posttraining epinephrine. Psychobiology, 19(3), 206-210. doi: 10.3758/BF03332069

Cooke, B. M., Chowanadisai, W., \& Breedlove, S. M. (2000). Post-weaning social isolation of male rats reduces the volume of the medial amygdala and leads to deficits in adult sexual behavior. Behavioural Brain Research, 117(1-2), 107 113. doi: 10.1016/S0166-4328(00)00301-6

Cunningham, M. G., Bhattacharyya, S., \& Benes, F. M. (2002). Amygdalo-cortical sprouting continues into early adulthood: Implications for the development of normal and abnormal function during adolescence. The Journal of Comparative Neurology, 453(2), 116-130. doi: 10.1002/cne.10376

Di Prisco, C. L., Lucarini, N., \& Dessì-Fulgheri, F. (1978). Testosterone aromatization in rat brain is modulated by social environment. Physiology \& Behavior, 20(3), 345-348. doi: 10.1016/0031-9384(78)90230-5

Djouma, E., Card, K., Lodge, D. J., \& Lawrence, A. J. (2006). The CRF1 receptor antagonist, antalarmin, reverses isolation-induced up-regulation of dopamine $\mathrm{D}_{2}$ receptors in the amygdala and nucleus accumbens of fawn-hooded rats. European Journal of Neuroscience, 23(12), 3319-3327. doi: 10.1111/j.14609568.2006.04864.x

Duffy, J. A., \& Hendricks, S. E. (1973). Influences of social isolation during development on sexual behavior of the rat. Animal Learning and Behavior, 1(3), 223-227. doi: 10.3758/BF03199079

Engel, A., \& Singer, W. (2001). Temporal binding and the neural correlates of sensory awareness. Trends in Cognitive Sciences, 5(1), 16-25. doi: 10.1016/S13646613(00)01568-0

Fanselow, M. S., \& LeDoux, J. E. (1999). Why we think plasticity underlying pavlovian fear conditioning occurs in the basolateral amygdala. Neuron, 23(2), 229-232. doi: 10.1016/s0896-6273(00)80775-8

Fernández-Guasti, A., Omaña-Zapata, I., Luján, M., \& Condés-Lara, M. (1994). Actions of sciatic nerve ligature on sexual behavior of sexually experienced and inexperienced male rats: Effects of frontal pole decortication. Physiology \& Behavior, 55(3), 577-581. doi: 10.1016/0031-9384(94)90119-8

Gerall, H. D., Ward, I. L., \& Gerall, A. A. (1967). Disruption of the male rat's sexual behavior induced by social isolation. Animal Behaviour, 15(1), 54-58. doi: 10.1016/S0003-3472(67)80010-1

Hernández-Arteaga, E., Hernández-González, M., Ramírez-Rentería, M. L., Almanza-Sepúlveda, M. L., Guevara, M. A., Silva, M. A., \& Jaime, H. B. (2016). Prenatal stress alters the developmental pattern of behavioral indices of sexual maturation and copulation in male rats. Physiology \& Behavior, 163, 251-257. doi: 10.1016/j.physbeh.2016.05.008

Hernández-González, M. (2000). Prepubertal genital grooming and penile erection in relation to sexual behavior of rats. Physiology \& Behavior, 71(1-2), 51-56. doi: 10.1016/S0031-9384(00)00320-6

Hernández-González, M., Guevara, M. A., Cervantes, M., Morali G., \& Corsi-Cabrera, M. (1998). Characteristic frecuency bands of the cortico-frontal EEG during the sexual interaction of the male rat as a result of factorial analysis. Journal of Physiology-Paris, 92(1), 43-50. doi: 10.1016/S0928-4257(98)80022-3

Hernández-González, M., Guevara, M. A., Ramírez-Rentería, M. L., \& HernándezArteaga, E. (2015). Post-weaning social isolation alters the development of behavioral indices of sexual maturation and leads to deficits in the sexual behavior of male rats. E-CUCBA, 3, 55-71. doi: 10.32870/e-cucba.v0i3.32 
Hernández-González, M., Hernández-Arteaga, E., Guevara, M. A., AlmanzaSepúlveda, M. L., Ramírez-Rentería, M. L., Arteaga-Silva, M., \& BonillaJaime, H. (2017). Prenatal stress supresses the prefrontal and amygdaline EEG changes associated with a sexually-motivated state in male rats. Physiology \& Behavior, 182(1), 86-92. doi: 10.1016/j.physbeh.2017.10.003

Hernández-González, M., Guevara, M. A., \& Ågmo, A. (2014a). Electroencephalographic activity during sexual behavior: a novel approach to the analysis of drug effects on arousal and motivation relevant for sexual dysfunctions. Pharmacology, Biochemestry, and Behavior, 121, 158-169. doi: 10.1016/j.pbb.2014.02.003

Hernández-González, M., Robles Aguirre, F. A., Guevara, M. A., Quirarte, G. L., \& Haro-Magallanes, P. (2014b). Basolateral Amygdala inactivation reduces sexual motivation in male rats during performance of a T-maze task with a sexual reward. Journal of Behavioral and Brain Science, 4(5), 223-233. doi: 10.4236/ jbbs.2014.45024

Hernández-González, M., Prieto-Beracoechea, C. A., Arteaga-Silva, M., \& Guevara, M. A. (2007). Different functionality of the medial and orbital prefrontal cortex during a sexually motivated task in rats. Physiology \& Behavior, 90(2-3), 450458. doi: 10.1016/j.physbeh.2006.10.006

Joëls, M. (1997). Steroid hormone and excitability in the mammalian brain. Frontiers in Neuroendocrinology, 18(1), 2-48. doi: 10.1006/frne.1996.0144

Kraus, J., Frick, A., Fischer, H., Howner, K., Fredrikson, M., \& Furmark, T. (2018). Amygdala reactivity and connectivity during social and non-social aversive stimulation in social anxiety disorder. Psychiatry Research: Neuroimaging, 280, 56-61. doi: 10.1016/j.pscychresns.2018.08.012

Lapiz, M. D. S., Fulford, A., Muchimapura, S., Mason, R., Parker, T., \& Marsden, C. A. (2003). Influence of postweaning social isolation in the rat on brain development, conditioned behavior, and neurotransmission. Neuroscience and Behavioral Physiology, 33(1), 13-29. doi: 10.1023/a:1021171129766

Leussis M. P., \& Andersen S. L. (2008). Is adolescence a sensitive period for depression? Behavioral and neuroanatomical findings from a social stress model. Synapse, 62(1), 22-30. doi: 10.1002/syn.20462

Lonc, G. (2012). Immunolocalisation of $\alpha$ and $\beta$ oestrogen receptors in basolateral amygdala of rabbit males. Bulletin of the Veterinary Institute in Pulawy, 56(1), 83-87. doi: 10.2478/v10213-012-0015-3

Montague, D., Weickert, C. S., Tomaskovic-Crook, E., Rothmond, D. A., Kleinman, J. E., \& Rubinow, D. R. (2009). Oestrogen Receptor $\alpha$ Localisation in the Prefrontal Cortex of Three Mammalian Species. Journal of Neuroendocrinology, 20(7), 893-903. doi: 10.1111/j.1365-2826.2008.01743.x

Moralí, G., Larsson, K., \& Beyer, C. (1977). Inhibition of testosterone-induced sexual behavior in the castrated male rat by aromatase blockers. Hormones \& Behavior, 9(3), 203-213. doi: 10.1016/0018-506X(77)90056-3

Muller, M., Van Den Beld, A. W., Van Der Schouw, Y. T., Grobbe, D. E., \& Lamberts, S. W. J. (2006). Effects of dehydroepiandrosterone and atamestane supplementation on frailty in elderly men. The Journal of Clinical Endocrinology \& Metabolism, 91(10), 3988-3991. doi: 10.1210/jc.2005-2433

Naghdi, N., Oryan, S., \& Etemadi, R. (2003). The study of spatial memory in adult male rats with injection of testosterone enanthate and flutamide into the basolateral nucleus of the amygdala in Morris water maze. Brain Research, 972(1-2), 1-8. doi: 10.1016/s0006-8993(03)02227-3

Nuñez, J. L., Huppenbauer, C. B., McAbee, M. D., Juraska, J. M., \& DonCarlos, L. L. (2003). Androgen receptor expression in the developing male and female rat visual and prefrontal cortex. Journal of Neurobiology, 56(3), 293-302. doi: 10.1002/neu.10236
Paxinos, G., \& Watson, C. (2007). The rat brain, in stereotaxic coordinates (6th edition). London: Elsevier.

Perelló, M., Chacon, F., Cardinali, D. P., Esquifino, A. I., \& Spinedi, E. (2006). Effect of social isolation on 24-h pattern of stress hormones and leptin in rats. Life sciences, 78(16), 1857-1862. doi: 10.1016/j.1fs.2005.08.029

Poblano, A., Hernández-Godínez, B., Arellano, A., Arteaga, C., Elías, Y., Morales, J., ... Poblano-Alcalá, A. (2004). Serum testosterone and electroencephalography spectra in developmental male rhesus Macaca mulatta Monkeys. Archives of Medical Research, 35(5), 406-410. doi: 10.1016/j.arcmed.2004.06.003

Pryce, C. R. (2008). Postnatal ontogeny of expression of the corticosteroid receptor genes in mammalian brains: Inter-species and intra-species differences. Brain Research Reviews, 57(2), 596-605. doi: 10.1016/j.brainresrev.2007.08.005

Retana-Márquez, S., Bonilla-Jaime, H., Vázquez-Palacios, G., Martínez-García, R., \& Velázquez-Moctezuma, J. (2003) Changes in masculine sexual behavior, corticosterone and testosterone in response to acute and chronic stress in male rats. Hormones \& Behaviour, 44(4), 327-337. doi: 10.1016/j.yhbeh.2003.04.001

del Río-Portilla, I., Ugalde, E., Juárez, J., Roldán, A., \& Corsi-Cabrera, M. (1997). Sex differences in EEG in adult gonadectomized rats before and after hormonal treatment. Psychoneuroendocrinology, 22(8), 627-642. doi: 10.1016/S03064530(97)00056-5

Schoenbaum, G., Chiba, A. A., \& Gallagher, M. (2000). Changes in functional connectivity in orbitofrontal cortex and basolateral amygdala during learning and reversal training. Journal of Neuroscience, 20(13), 5179-5189. doi: 10.1523/JNEUROSCI.20-13-05179.2000

Schulz, K. M., Richardson, H. N., Zehr, J. L., Osetek, A. J., Menard, T. A., \& Sisk, C. L. (2004). Gonadal hormones masculinize and defeminize reproductive behaviors during puberty in the male Syriam hamster. Hormones \& Behavior, 45(4), 242-249. doi: 10.1016/j.yhbeh.2003.12.007

Serra, M., Pisu, M. G., Floris, I., \& Biggio, G. (2005). Social isolation-induced changes in the hypothalamic-pituitary-adrenal axis in the rat. Stress, 8(4), 259264. doi: $10.1080 / 10253890500495244$

Stratakis, C. A., \& Chrousos, G. P. (1995). Neuroendocrinology and pathophysiology of the stress system. Annals of New York Academy of Sciences, 771(1), 1-18. doi: 10.1111/j.1749-6632.1995.tb44666.x

Vanderwolf, C. H. (1969). Hippocampal electrical activity and voluntary movement in the rat. Electroencephalographic and Clinical Neurophysiology, 26(4), 407418. doi: 10.1016/0013-4694(69)90092-3

Ventura-Aquino, E., \& Paredes, R. G. (2017). Animal models in sexual medicine: The need and importance of studying sexual motivation. Sexual Medicine Reviews, 5(1), 5-19. doi: 10.1016/j.sxmr.2016.07.003

Vetulani, J. (2013). Early maternal separation: A rodent model of depression and a prevailing human condition. Pharmacological Reports, 65(6), 1451-1461. doi: 10.1016/S1734-1140(13)71505-6

Wang, Y. C., Ho, U. C., Ko, M. C., Liao, C. C., \& Lee, L. J. (2012). Differential neuronal changes in medial prefrontal cortex, basolateral amygdala and nucleus accumbens after postweaning social isolation. Brain Structure \& Function, 217(2), 337-351. doi: 10.1007/s00429-011-0355-4

Zhang, W., \& Rosenkranz, J. A. (2012). Repeated restraint stress increases basolateral amygdala neural activity in an age-dependent manner. Neuroscience, 226, 459474. doi: 10.1016/j.neuroscience.2012.08.051 